\title{
Modern Agrochemicals Influence Bioaccumulation of Incurred DDT Soil Residues in Pumpkins - Residue Risk or a Chance for Phytoremediation?
}

\author{
Julia Neitsch ${ }^{1}$, Wolfgang Schwack ${ }^{2}$, Philipp Weller ${ }^{1}$ \\ ${ }^{1}$ Institute for Instrumental Analytics and Bioanalysis, Mannheim University of Applied Science, Paul Wittsack- \\ Strasse 10, 68163 Mannheim, Germany \\ ${ }^{2}$ Institute of Food Chemistry, University of Hohenheim, Garbenstrasse 28, 70593 Stuttgart
}

*Corresponding Author: Philipp Weller, Institute for Instrumental Analytics and Bioanalysis, Mannheim

University of Applied Science, Paul-Wittsack-Strasse 10, 68163 Mannheim, Germany

\begin{abstract}
Although banned more than 50 years ago, residues of first generation organochlorine pesticide residues, such as DDT are still found in agricultural soils all over the world. Phytoremediation is a potential remediation strategy, using plants to remove these residues from the soils. One limiting factor is the low mobility and bioavailability of lipophilic compounds for plants. Soil mobility can be significantly increased by the application of surfactants to the soils. Agrochemicals, in particular crop protection formulations commonly contain major amounts of surfactants as adjuvants, a fact which so far has not been considered an influencing factor for the mobilization of organochlorine contaminants such as DDT. This study evaluated the influence of commonly applied agrochemical products on the bioavailability of DDT and its metabolites in pumpkins in an open-field trial. To compare different typically used products, organic farming pesticides were compared against conventional formulations.
\end{abstract}

Keywords: DDT, Persistent organic pollutants, Phytoremediation, Pesticide treatment, Agricultural practice, Modern pesticide treatment, Pumpkins.

\section{INTRODUCTION}

The extensive use of the so called "first generation" organochlorine pesticides, such as DDT $(1,1,1$ trichlor-2,2-bis (4-chlorphenyl)ethan), Lindane, Toxaphene or Mirex during the mid of the last century shaped a delicate heritage of contaminants for modern agronomists. While today, these substances are mostly banned for agricultural use by the 2004 Stockholm Convention on Persistent Organic Pollutants (POPs), some few are still used in developing countries, mainly due to their favorable costs and a still distinct efficacy. This is in particular the case for DDT, the main Malaria vector control agent in third world countries [1]. While western nations withdrew registrations for agricultural use already in the 1970s and 1980s, still even after almost half a century's time after the use ban of DDT, the trailblazer of the "dirty dozen" still haunts agronomists with its longevity in contaminated soils.

Due to the high persistence of DDT and its metabolites DDE (1-chlor-4-(2, 2-dichlorphenyl-1(4chlorphenyl) ethenyl) benzene) and DDD (1-chlor-4-(2,2-dichlor-1-(4-chlorphenyl) ethyl) benzol) ("DDX") against microbial and chemical degradation, still distinct quantities of DDX are found in many soils all over the world [2-5]. The main hot spots are found in Asia [2,3], America [4,5] and southern Africa, while levels in Western Europe [6,7] are comparably low. In combination with the highly lipophilic character ( $\log \mathrm{K}_{\mathrm{ow}} \mathrm{DDT}=6,91$ [8]), DDX remain adsorbed mainly to soil organic matter and therefore, relatively static in upper soil layers. It is however known that lipophilic contaminants adsorbed to the dissolved organic carbon (DOC) fraction of the soil show an increased water solubility and therefore, mobility. This mobility may be significantly influenced by the application of surfactants, which was demonstrated in a number of studies [9-15], where surfactant/ water mixtures were directly applied to soil samples or used to extract soils. Such mixtures are commercially used for the removal of non-aqueous phase liquids (NAPLs) [16] from highlycontaminated soils, e.g. resulting from oil leakages. This process is commonly performed by the 
injection of a hot and pressurized surfactant/water mixture into the main site of contamination, emulsifying the NAPLs and subsequently, the removal of the emulsion by pumps [9-13]. While this is applicable for (expensive) building land as an alternative to removal and extraction, this is not feasible for agricultural soils. Costs are high and the treatments impair the soil microstructure. In the context of remediation, a mobilization of organic contaminants, such as DDX from soil organic matter is discussed as a first step towards depletion [17,9,18-21,12,13,22].

Interestingly, not all of the evaluated surfactants featured the same efficacy in terms of mobilization. In particular, non-ionic surfactants of the polysorbate type (Tweens) were shown $[23,13]$ to be most effective in increasing mobility of DDX.

A potential alternative is the phytoremediation which refers to the cultivation of specific plants with a high bioaccumulation tendency for substance groups such as lipophilic contaminants $[24,25]$ or heavy metals [26]. These plants are used as a vehicle to deplete contaminated soils by continuous extraction over a period of several years. A number of studies $[6,27,28,5]$, especially on the phytoremediation of DDX contaminated soils have been published over the last years, which demonstrated that plants from the genus Cucurbita and Cucumis generally show a high tendency to accumulate DDX and other POPs from the soil. It was found that Cucurbitacea secrete root exudates with emulsifying properties, which led to higher accumulation rates [29,30]. Most of these studies focused either on the identification of the most efficient cultivar $[27,31,32]$ or on how to influence accumulation rates by adding organic matter, such as peat, potting soil or activated carbon [27,33]. In particular, Cucurbita pepo has been described as a high accumulation cultivar for DDX in numerous studies $[32,28,6,34,35,31,36,36-38,27]$.

A drawback of phytoremediation strategies is the low bioaccumulation rate [39,30], due to the fact that the passive uptake of lipophilic compounds is limited by the bioavailability of the contaminants in the soil or soil water. DDX feature a water solubility in the lower $\mu \mathrm{g} / \mathrm{L}$ level (DDT: $1.2 \mu \mathrm{g} / \mathrm{L}$ ), which limits bioavailability in general. Wu et al. evaluated the efficacy of alfalfa, inoculated with arbuscular mycorrhiza to biodegrade DDX and other organochlorine pesticides (OCPs) in the soil after mobilization with Triton X-100 [40]. It could be demonstrated that the degradation efficacy was significantly increased when non-ionic surfactants were used.

So far, published studies have not evaluated a potential benefit of an application with modern pesticides with a high amount of surfactant in combination with crops of a high DDX accumulation tendency, such as pumpkins or squash. It is at least probable that the high amount of surfactant, in particular with Tween type surfactants and vegetable oil, may lead to higher accumulation rates into plants, even without biotechnological enhancement.

Remediating surfactant treatments are no common practice in modern agriculture and would be subject to regulatory restrictions in most countries. However, surfactants are already widely used in modern agriculture as part of pesticide formulations. Most of these formulations contain non-ionic surfactants, such as polysorbates or polyethylene glycol based types.

In a previously published study, conducted in 2015, [41], we were able to demonstrate that a typical modern pesticide protocol may lead to a significantly higher extractability of DDX in the soil and to increased levels in the soil water fraction. This was in particular the case for pesticide formulations with a high polysorbate (Tween) content and resulted in a threefold increase of the DDX concentrations in the water fraction, which could lead to a higher bioavailability in the cultivated crops.

While the bioaccumulation of DDX in food crops is naturally considered an adverse effect and could lead to residual levels [42] above typical acceptance specifications, it could be a most useful effect in terms of remediation of contaminated agricultural soils.

The aim of this study was to evaluate the influence of a typical pesticide regime as generally used in cultivation of crops on the bioaccumulation behavior of Cucurbita pepo under real-life conditions in a field trial. In order to assess the influence of surfactants commonly used in pesticide formulations, a conventional treatment was compared to an organic approach, as these concepts significantly differ in the type of agrochemicals used. The trial described here was conducted in 2015 on the same trial section one year after the original study [41], specifically focusing on the observation of potential effects in the harvested crops. 
Modern Agrochemicals Influence Bioaccumulation of Incurred DDT Soil Residues in Pumpkins Residue Risk or a Chance for Phytoremediation?

\section{EXPERIMENT}

\subsection{Chemicals and Reagents}

All solvents were HPLC grade. Acetone, dichloromethane, methanol and n-hexane were purchased from VWR (Bruchsal, Germany). Pure standards of quintozene, DDT, DDD and DDE were obtained from Sigma-Aldrich (Munich, Germany), PBC80 from Dr. Ehrenstorfer (Augsburg, Germany). Sea sand was purchased from PanReac AppliChem (Darmstadt, Germany), Florisil (mesh 100-200) from Thermo Fisher Scientific (Karlsruhe, Germany).

\subsection{Trial Site, Agrochemical Treatments and Pumpkin Cultivation}

The trial field was located in Rhineland-Palatinate in southwestern Germany and measured 0.96 ha. The soil was classified as silty loam with $1.4 \%$ humus content, $\mathrm{pH} 7.6$, average residual DDX levels of the section ranged between $40-50 \mu \mathrm{g} / \mathrm{kg}$ dry matter. For cultivation, the soil was plowed $30 \mathrm{~cm}$ deep before planting. All sections were irrigated with comparable amounts of water. The cultivation area was divided into three sections: a control area without pesticide treatment, a second area with a conventional pesticide treatment as approved for pumpkins in Germany, and a third section treated with plant protection products according to organic farming guidelines (Fig 1). To avoid crosscontamination between the control zone and the treated zones, an untreated corridor of $2 \mathrm{~m}(1+1 \mathrm{~m})$ width was established. Sampling was carried out in $\mathrm{W}$-shape in each of the respective sections. A technical replicate was generated from each sampling point.

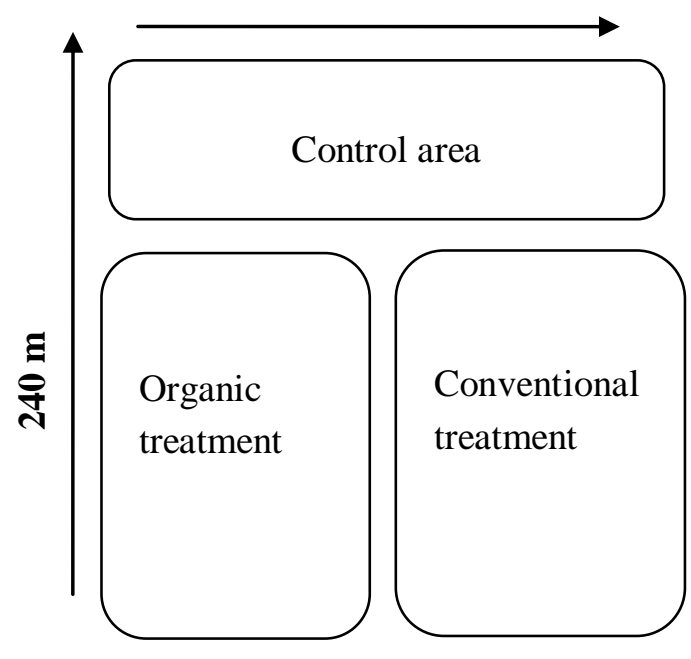

Figure 1. Trial field setup

All sections were fertilized by a conventional fertilizer (Nitrophoska perfect $15+5+20,800 \mathrm{~kg} / \mathrm{ha}$ ). The application protocol of agrochemicals is summarized in table 1. The application of agrochemicals were performed according to official guidelines and in compliance with good agricultural practice.

Approx. 10,000 seedlings of the pumpkin cultivar Cucurbita pepo (Sorcerer F1, 1 plant/square meters) were cultivated on the trial field. Seeds were obtained commercially (bobby-seeds.com), the seedlings were cultivated by a local breeder. During the cultivation period, plant samples (shoot, leafs and root) were taken one week after each pesticide treatment and after harvest.

Table 1. Application protocol and product properties

\begin{tabular}{|c|c|c|c|}
\hline $\begin{array}{l}\text { Application } \\
\text { type }\end{array}$ & $\begin{array}{l}\text { Active substances and } \\
\log \text { kow } * *\end{array}$ & Other main components* & Application rate \\
\hline Conventional & $\begin{array}{l}\text { thiacloprid }(480 \mathrm{~g} / \mathrm{L}) \\
\log 1.6^{* *} \text { Kow }\end{array}$ & polyethylene glycol based (5-10\%) & week 6; 0.5 L/ha \\
\hline Conventional & $\begin{array}{l}\text { azoxystrobin }(250 \mathrm{~g} / \mathrm{L}) \\
\log 2.5^{* *} \text { Kow }\end{array}$ & $\begin{array}{l}\text { fatty alcohol ethoxylates }(10-18 \%) \\
\text { naphthalene sulfonic acid based }(1-5 \%)\end{array}$ & week $6 ; 1 \mathrm{~L} / \mathrm{ha}$ \\
\hline Conventional & $\begin{array}{l}\text { difenconazol }(125 \mathrm{~g} / \mathrm{L}) \text {, } \\
\text { azoxystrobin }(200 \mathrm{~g} / \mathrm{L}) \\
\log 4.4 * * \text { Kow }\end{array}$ & $\begin{array}{l}\text { fatty alcohol ethoxylates , (C16-18, 15- } \\
25 \%)\end{array}$ & week $8 ; 1 \mathrm{~L} / \mathrm{ha}$ \\
\hline Conventional & $\begin{array}{l}\text { trifloxystrobin }(500 \mathrm{~g} / \mathrm{L}) \\
\log 4.5^{* *} \text { Kow }\end{array}$ & $\begin{array}{l}\text { sodium dibutylnaphthalene sulphonate } \\
(1-25 \%)\end{array}$ & week $8 ; 0.5 \mathrm{~L} / \mathrm{ha}$ \\
\hline
\end{tabular}


Modern Agrochemicals Influence Bioaccumulation of Incurred DDT Soil Residues in Pumpkins Residue Risk or a Chance for Phytoremediation?

\begin{tabular}{|l|l|l|l|}
\hline Conventional & $\begin{array}{l}\text { thiacloprid }(480 \mathrm{~g} / \mathrm{L}) \\
\log 1.6^{* *} \text { Kow }\end{array}$ & polyethylene glycol based $(5-10 \%)$ & week 8; 0.2 L/ha \\
\hline Organic & $\begin{array}{l}\text { azadirachtin A }(10 \mathrm{~g} / \mathrm{L}) \\
\log 1.09^{* *} \mathrm{Kow}\end{array}$ & $\begin{array}{l}\text { tween type }(>70 \%) \\
\text { plant oil }(15-20 \%)\end{array}$ & $\begin{array}{l}\text { week } 5,7,9 ; 2.5 \\
\mathrm{~L} / \mathrm{ha}\end{array}$ \\
\hline Organic & $\mathrm{KHCO}_{3}(850 \mathrm{~g} / \mathrm{kg})$ & - & week $11 ; 3 \mathrm{~kg} / \mathrm{ha}$ \\
\hline Organic & sulfur $(800 \mathrm{~g} / \mathrm{kg})$ & - & week $11 ; 3 \mathrm{~kg} / \mathrm{ha}$ \\
\hline
\end{tabular}

*Composition data was obtained either via MSDS or by in-house measurements

** Source: PubChem

\subsection{Preparation and Extraction of Plant Samples}

Prior to analysis, soil particles were removed from the samples by cleansing with water. For extraction, $10 \mathrm{~g}$ of fresh plant sample were homogenized using liquid nitrogen, transferred into a falcon tube and was filled up to $50 \mathrm{~mL}$ with methanol. PCB80 was added as internal standard, and the samples were shaken in an overhead shaker for 15 minutes. After centrifugation (3000 rpm/10 min), the supernatant was diluted with $40 \mathrm{~mL}$ deionized water. Prior to sample clean-up, SPE cartridges (C18ec, Machery-Nagel, Dueren Germany) were preconditioned with $5 \mathrm{~mL}$ methanol and subsequently with $5 \mathrm{~mL}$ deionized water. Subsequently, sample solutions were loaded onto the cartridges, the columns were washed with one column volume of deionized water and dried under vacuum for $10 \mathrm{~min}$. The elution was performed with $1 \mathrm{~mL}$-hexane containing $1 \mathrm{mg} / \mathrm{L}$ quintozene as a quality indicator for the chromatographic system. Quintozene is highly susceptible to column degradation effects and shows peak splitting, which was used as cut-off criterion.

\subsection{Preparation and Extraction of Soil Samples}

The extraction of the dried soil samples was performed by an accelerated solvent extraction (ASE) system (Dionex ASE 200, Idstein, Germany). $20 \mathrm{~g}$ of soil was mixed with $100 \mu \mathrm{L}$ of PCB80 extraction standard solution $(1 \mathrm{mg} / \mathrm{L})$ and transferred into $33 \mathrm{~mL}$ stainless steel extraction cells, which were prefilled with $5 \mathrm{~g}$ of sea sand to avoid compression of the cell contents. The extraction program was performed according to Tao et al. [2].

The ASE extracts were evaporated to dryness in a rotary evaporator and redissolved in $40 \mathrm{~mL}$ of $\mathrm{n}$ hexane containing $8 \%(\mathrm{v} / \mathrm{v})$ acetone. Sample cleanup was performed on a column packed with $13 \mathrm{~g}$ of dried Florisil. The soil extract was loaded onto the column and eluted with $30 \mathrm{~mL}$ of $\mathrm{n}$-hexane, containing $15 \%$ acetone $(\mathrm{v} / \mathrm{v})$. The purified extracts were evaporated to dryness, redissolved in $1 \mathrm{~mL}$ of an $\mathrm{n}$-hexane solution of quintozene $(1 \mathrm{mg} / \mathrm{L})$ as an internal standard and filtered through a $0.45 \mu \mathrm{m}$ PTFE membrane filter.

\subsection{Sample Analysis}

DDT and its metabolites DDE and DDD were determined by gas chromatography coupled to a mass spectrometer (Agilent 6890/5973, Waldbronn, Germany), operated in EI ionization mode. The chromatographic parameters were as follows: initial temperature $50{ }^{\circ} \mathrm{C}$, hold for $4 \mathrm{~min}$; $10^{\circ} \mathrm{C} / \mathrm{min}$ to $230{ }^{\circ} \mathrm{C} ; 5{ }^{\circ} \mathrm{C} / \mathrm{min}$ to $280{ }^{\circ} \mathrm{C}$ hold $10 \mathrm{~min}$, a sample volume of $1 \mu \mathrm{L}$ was injected by pulsed splitless injection at $280{ }^{\circ} \mathrm{C}$. The carrier gas was helium with a flow of $5 \mathrm{~mL} / \mathrm{min}$. The temperature of the ion source and the quadrupole were $230{ }^{\circ} \mathrm{C}$ and $150{ }^{\circ} \mathrm{C}$, respectively. The retention times of quintozene, p,p'-DDE, PCB80, p,p'-DDD and p,p'-DDT were 19.39, 22.38, 23.50, 24.24 and 25.34 min.

\subsection{Calibration Curves, Limit of Quantification and Recovery}

The generation of a calibration curve was performed by diluting a DDX stock solution of $10 \mathrm{mg} / \mathrm{L}$ with $\mathrm{n}$-hexane containing quintozene $(1 \mathrm{mg} / \mathrm{L})$ to the following concentrations: $0.1,0.5,1.0,2.0,4.0$ $\mathrm{mg} / \mathrm{L}$. The calculated correlation coefficients generally were higher than 0.99 . The limits of quantification (LOQ) for DDT (5 ng/L), DDE (0.5 ng/L) and DDD (0.5 ng/L) were calculated from a signal to noise ratio of $>10$. Extraction recovery rates were calculated based on the PCB80 internal standard and were accepted between $70-120 \%$ according to SANCO guidelines [43].

\subsection{Statistical Analysis}

For all calculations, mean values of DDX levels from replicate samples were used together with the respective standard deviations. The analytical data are depicted in form of box-whisker plots. All data 
were analyzed for homogeneity of variance and normal distribution by a one-way analysis of variance (ANOVA) by a Tukey's comparison test. All statistical analysis was performed using GraphPad Prism (Version 5.04, GraphPad Software, Inc, CA, USA). Level of significance in all cases was P < 0.05 .

\section{RESULTS AND DISCUSSION}

The DDX residual level of the trial field ranged between 40 and $50 \mu \mathrm{g} / \mathrm{kg}$ in dry matter which was comparable to the levels detected in a previously published study [27]. The three sections, control, conventional and organic, were not statistically differentiable $(\mathrm{P}>0.05)$.

Studies [35,34] demonstrated that cultivation density has a direct impact on the accumulation tendency. Therefore, the number of plants per square meters was kept comparable on all of the three sections.

To assess the DDX uptake behavior over the cultivation period in dependence of the agrochemical treatment, plants were sampled from all three sections in June, July and shortly before harvest in September, followed by GC-MS analysis. Roots were sampled in June and July only, as the root system of pumpkins rots during the ripening process of the fruits. Parallel to the plant samples, soil samples were taken before and after each pesticide application. Figure 2 shows the level of accumulated DDX in the roots. It is clearly visible that within these four weeks, the DDX level increased significantly in the roots of the plants grown on the organic section $(\mathrm{P}<0.05)$. The DDX level in samples from the conventionally treated, as well as from the untreated control area were statistically not differentiable ( $\mathrm{P}>0.05$ ), but a tendency to an increase is visible in all cases. In comparison, the DDX level in the roots of plants from the organic section was nearly twice as high compared to the conventional and more than two fold higher than levels of root samples from the control section.

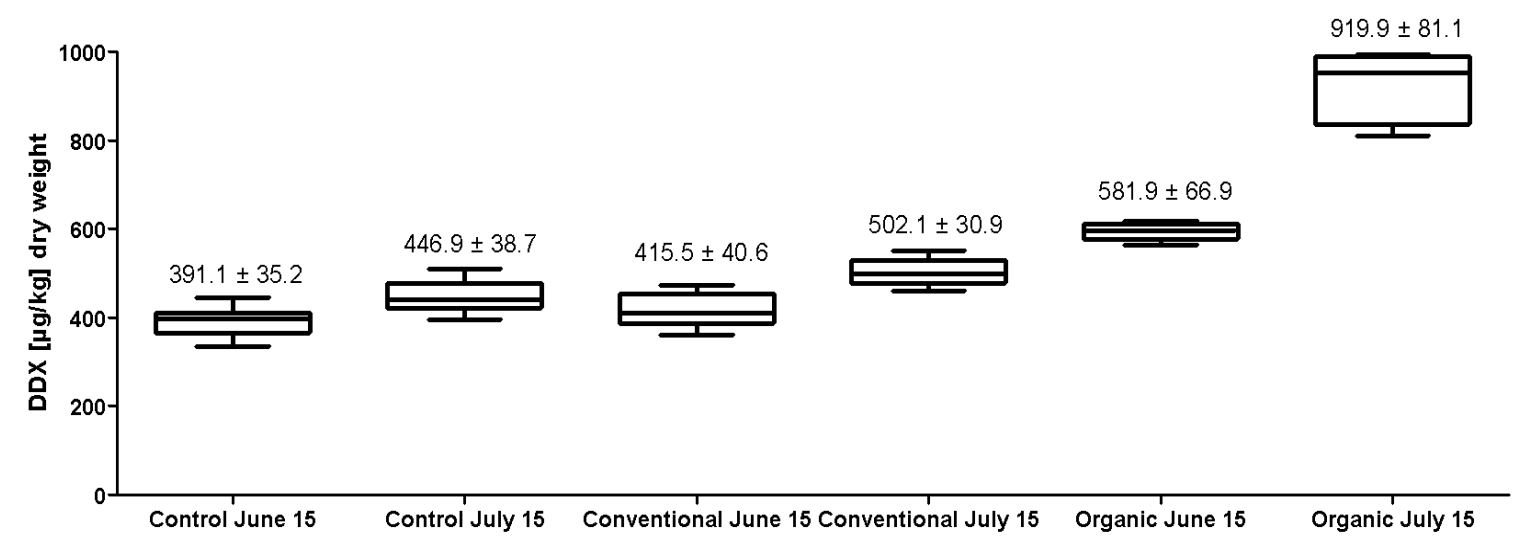

Figure 2. DDX levels in roots, band inside the box represents the median. DDX level of control and conventional section are not differentiable $(P>0.05)$. The organically grown plants show a significant difference in the two sampling points $(n=8$, each). All data showed normal distribution.

Samples taken from the shoots analyzed between 15th of June and 20th of July showed a comparable situation, however, the overall DDX level was clearly lower as compared to the roots (Fig. 2). This gradient effect is presumably the result from the increasing distance between roots and green plant parts while growing, which can also be seen in the contents of the fruits, which were even lower than roots and shoots (Fig. 3). This effect was already described in the literature [27]. Between June and July (Fig. 3), a decrease in the DDX levels was observable in all sections, while in the time between July and September, a significant increase of the levels was observed in all plants. The decreasing effect is most likely a result from the fast plant growth and mass gain during the time between June and July. Transportation within the plant is water based, therefore, lipophilic compounds as DDX move slowly within the plant, which reduces the transportation efficacy to the upper plant segments, in particular when the plant is in the growth state. Accordingly, the results of September show that the DDX levels rise again, as plant growth stops during fruit ripening. 


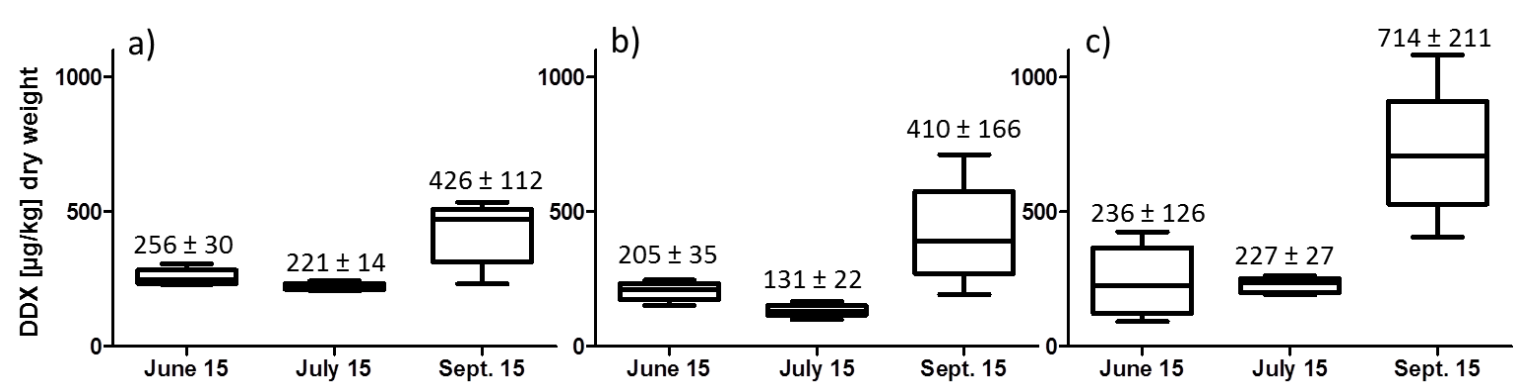

Figure 3. DDX levels in shoots, band inside the box represents the median. The DDX amounts of the control, conventionally and organically grown plants show no significant differences in the first two sampling points. A significant difference is determined in the last sampling point in all three sections $(a)$ control $n=10, b)$ conventional $n=25$, c) organic $n=25$ ). All data showed normal distribution.

The ripened pumpkins were harvested in September and showed a comparable behavior as the shoots and roots. Fruits from the organic section accumulated more than twice as much DDX as the control and conventionally treated pumpkins (Fig 4).

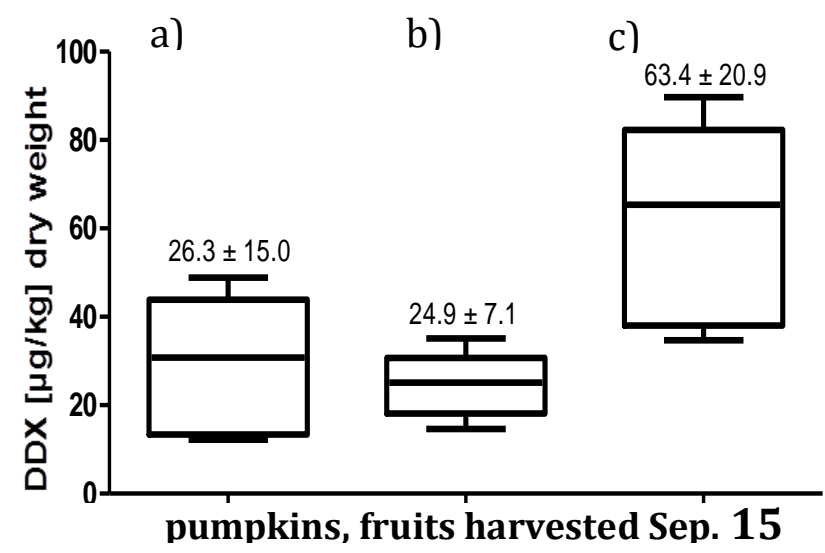

Figure 4. Distribution of the DDX amount in pumpkin fruits, band inside the box represents the median. The DDX amount of the control and the conventionally grown pumpkin fruits show no significant differences. The organically grown pumpkin fruits show a significant difference compared to the control and conventionally grown cultivars (a) control $n=8, b$ ) conventional $n=12$, c) organic $n=12$ )

The soil samples from the three sections featured nearly the same behavior as previously described [41]: after the first treatment with the formulation of high Tween content, the extractability of DDX from the soil samples significantly $(\mathrm{P}<0.05)$ increased by a factor of 1.5 (Fig 4), while the conventionally treated section and the control section showed no significant differences $(\mathrm{P}>0.05)$. It is clearly visible, that the mobilization effect in the soil led to a higher DDX level in the plant, which can be interpreted as a direct connection between a higher mobility in soil and the bioavailability for susceptible plants, such as Cucurbitacea. This observation demonstrates that a regular pesticide treatment with particular formulations or formulation types indeed has a direct impact on the bioaccumulation of old incurred DDX residues, at least in the pumpkin cultivar used in this study. This observation is in line with the observations of a study conducted on the same trial site one year before, where the main focus was set on the analysis of the soil [41].

A measure for the bioaccumulation behavior is the bioaccumulation factor (BCF), which is obtained as the ratio of the DDX level in roots, shoots or fruits and the DDX level in the soil. The BCFs for all compartments were calculated on this basis and are given in table 3 . The BCFs for the organic section have increased by a factor of $1.9-2.4$ compared to the control section, while the conventional section only showed a BCF increase up to 1.2. These results indicate that the agrochemical treatment in the organic section had a major influence on the accumulated amount of DDX, because the initial situation of the three areas was comparable. This is in line with a former study [41], which demonstrated that the application of formulations based on polysorbates of the Tween type in combination with plant oils may lead to significant increases in the mobility of DDX in agricultural soils, as well as in the soil water phase.

This observation can be interpreted in such that the key driver for bioaccumulation into plants is not only the accumulation tendency of the plant itself, but is significantly influenced by an increased 
Modern Agrochemicals Influence Bioaccumulation of Incurred DDT Soil Residues in Pumpkins Residue Risk or a Chance for Phytoremediation?

mobility or availability in the soil or the soil water, respectively. This is generally in line with studies published by Paul et al. [5], who observed the highest bioaccumulation factors in pumpkins grown on mid-level contaminated soils (up to $5083 \mathrm{ng} / \mathrm{g}$ ), while the BCF values did not increase linearly with even higher contaminations (soils with up to $10,192 \mathrm{ng} / \mathrm{g}$ ). In table 2, the individual contents of the metabolites in the analyzed compartments are given, which clearly show that DDE was predominantly accumulated into the plant and also transported into the compartments farther away from the soil, while DDD was only found in roots and shoots, but not in the pumpkin fruits.

Table 2. DDX Levels in different plant compartments ${ }^{a}$ and soil samples.

\begin{tabular}{|c|c|c|c|c|}
\hline & & \begin{tabular}{|l|} 
Control \\
\end{tabular} & Conventional & Organic \\
\hline \multirow{15}{*}{$\begin{array}{l}\text { Shoot dry weight } \\
{[\mu \mathrm{g} / \mathrm{kg}]}\end{array}$} & June & $\mathrm{n}=10$ & $\mathrm{n}=25$ & $\mathrm{n}=25$ \\
\hline & DDT & - & - & - \\
\hline & DDE & \begin{tabular}{|l|}
$208.9 \pm 20.1$ \\
\end{tabular} & $190.7 \pm 36.1$ & $209.1 \pm 121.8$ \\
\hline & DDD & $12.9 \pm 6.6$ & $13.9 \pm 6.0$ & $27.2 \pm 18.6$ \\
\hline & $\sum$ DDX & $221.8 \pm 22.9$ & $204.6 \pm 35.3$ & $236.3 \pm 125.5$ \\
\hline & July & $\mathrm{n}=10$ & $\mathrm{n}=25$ & $\mathrm{n}=25$ \\
\hline & DDT & - & - & - \\
\hline & DDE & $290.9 \pm 61.1$ & $121.1 \pm 20.3$ & $200.7 \pm 25.9$ \\
\hline & DDD & $11.9 \pm 0.9$ & $9.9 \pm 3.2$ & $26.8 \pm 4.2$ \\
\hline & $\sum$ DDX & $302.9 \pm 61.2$ & $130.9 \pm 20.3$ & $227.5 \pm 27.0$ \\
\hline & September & $\mathrm{n}=10$ & $\mathrm{n}=25$ & $\mathrm{n}=25$ \\
\hline & DDT & - & - & - \\
\hline & DDE & $424.6 \pm 67.5$ & $406.3 \pm 165.1$ & $699.3 \pm 231.6$ \\
\hline & DDD & $4.9 \pm 1.1$ & $3.9 \pm 2.6$ & $5.2 \pm 3.9$ \\
\hline & $\sum$ DDX & $429.5 \pm 67.3$ & $410.3 \pm 166.0$ & $704.5 \pm 234.5$ \\
\hline \multirow{10}{*}{$\begin{array}{l}\text { Root dry weight } \\
{[\mu \mathrm{g} / \mathrm{kg}]}\end{array}$} & June & $\mathrm{n}=8$ & $\mathrm{n}=8$ & $\mathrm{n}=8$ \\
\hline & DDT & - & - & - \\
\hline & DDE & $378.9 \pm 36.2$ & $404.9 \pm 38.4$ & $572.2 \pm 67.0$ \\
\hline & DDD & $12.2 \pm 3.9$ & $10.6 \pm 2.7$ & $9.7 \pm 1.2$ \\
\hline & $\sum$ DDX & $391.1 \pm 35.2$ & $415.5 \pm 40.6$ & $581.9 \pm 66.9$ \\
\hline & July & $\mathrm{n}=8$ & $\mathrm{n}=8$ & $\mathrm{n}=8$ \\
\hline & DDT & - & - & - \\
\hline & DDE & $430.2 \pm 36.6$ & $483.6 \pm 30.9$ & $895.1 \pm 78.9$ \\
\hline & DDD & $16.7 \pm 5.9$ & $18.5 \pm 4.4$ & $24.9 \pm 3.4$ \\
\hline & $\sum$ DDX & $446.9 \pm 38.7$ & $502.1 \pm 30.9$ & $919.9 \pm 81.1$ \\
\hline \multirow{6}{*}{$\begin{array}{l}\text { Fruit dry weight } \\
{[\mu \mathrm{g} / \mathrm{kg}]}\end{array}$} & September & $\mathrm{n}=8$ & $\mathrm{n}=12$ & $\mathrm{n}=12$ \\
\hline & DDT & - & - & - \\
\hline & DDE & $26.3 \pm 15.0$ & $24.9 \pm 7.1$ & $63.4 \pm 20.9$ \\
\hline & DDD & - & - & - \\
\hline & $\sum$ DDX & $26.3 \pm 15.0$ & $24.9 \pm 7.1$ & $63.4 \pm 20.9$ \\
\hline & & \begin{tabular}{|l|} 
Control \\
\end{tabular} & Conventional & Organic \\
\hline \multirow{17}{*}{$\begin{array}{l}\text { Soil dry weight } \\
{[\mu \mathrm{g} / \mathrm{kg}]}\end{array}$} & Before treatment & $\mathrm{n}=3$ & $\mathrm{n}=3$ & $n=3$ \\
\hline & DDT & $8.7 \pm 0.7$ & $10.8 \pm 2.8$ & $11.9 \pm 0.9$ \\
\hline & DDE & $32.3 \pm 2.9$ & $32.2 \pm 1.9$ & $30.9 \pm 4.4$ \\
\hline & DDD & $1.6 \pm 0.5$ & $1.3 \pm 0.3$ & $2.1 \pm 0.2$ \\
\hline & $\sum$ DDX & $42.6 \pm 1.9$ & $44.3 \pm 0.9$ & $44.9 \pm 3.3$ \\
\hline & June & $\mathrm{n}=3$ & $\mathrm{n}=3$ & $\mathrm{n}=3$ \\
\hline & DDT & $10.7 \pm 1.9$ & $11.8 \pm 0.8$ & $14.5 \pm 2.2$ \\
\hline & DDE & $31.3 \pm 1.9$ & $30.2 \pm 4.0$ & $47.3 \pm 6.2$ \\
\hline & DDD & $1.8 \pm 0.3$ & $1.6 \pm 0.2$ & $1.7 \pm 0.3$ \\
\hline & $\sum \mathbf{D D X}$ & $43.8 \pm 3.6$ & $43.5 \pm 4.5$ & $63.6 \pm 4.9$ \\
\hline & July & $\mathrm{n}=3$ & $\mathrm{n}=3$ & $\mathrm{n}=3$ \\
\hline & DDT & $10.1 \pm 3.7$ & $10.4 \pm 1.5$ & $11.9 \pm 1.4$ \\
\hline & DDE & $31.4 \pm 1.6$ & $29.7 \pm 1.3$ & $44.4 \pm 3.1$ \\
\hline & DDD & $1.6 \pm 0.1$ & $1.5 \pm 0.2$ & $1.7 \pm 0.3$ \\
\hline & $\sum$ DDX & $43.1 \pm 5.6$ & $41.5 \pm 2.9$ & $58.1 \pm 2.6$ \\
\hline & August & $\mathrm{n}=3$ & $\mathrm{n}=3$ & $\mathrm{n}=3$ \\
\hline & DDT & $11.5 \pm 2.5$ & $11.0 \pm 1.2$ & $13.1 \pm 1.5$ \\
\hline
\end{tabular}


Modern Agrochemicals Influence Bioaccumulation of Incurred DDT Soil Residues in Pumpkins Residue Risk or a Chance for Phytoremediation?

\begin{tabular}{|l|l|l|l|l|}
\hline & DDE & $33.8 \pm 6.1$ & $33.7 \pm 1.1$ & $47.8 \pm 1.1$ \\
\cline { 2 - 5 } & DDD & $1.6 \pm 0.2$ & $1.7 \pm 0.4$ & $2.2 \pm 0.2$ \\
\cline { 2 - 5 } & LDDX & $\mathbf{4 6 . 9} \pm \mathbf{4 . 3}$ & $\mathbf{4 6 . 5} \pm \mathbf{1 . 8}$ & $\mathbf{6 3 . 1} \pm \mathbf{0 . 9}$ \\
\cline { 2 - 5 } & Harvest & $\mathrm{n}=3$ & $\mathrm{n}=3$ & $\mathrm{n}=3$ \\
\cline { 2 - 5 } & DDT & $10.9 \pm 2.6$ & $11.0 \pm 1.3$ & $41.4 \pm 2.4$ \\
\cline { 2 - 5 } & DDE & $31.4 \pm 5.8$ & $30.3 \pm 6.6$ & $2.0 \pm 2.2$ \\
\cline { 2 - 5 } & DDD & $1.9 \pm 0.4$ & $1.8 \pm 0.2$ & $\mathbf{6 3 . 0} \pm \mathbf{2 . 5}$ \\
\cline { 2 - 4 } & LDDX & $\mathbf{4 4 . 3} \pm \mathbf{6 . 9}$ & $\mathbf{4 3 . 1} \pm \mathbf{5 . 8}$ & \\
\hline
\end{tabular}

${ }^{a}$ Data are given as mean values \pm standard deviation.

A direct comparison of the results in table 3 with literature data is complex, as most of the studies were carried out with higher contaminated soils in the range of $150-10,192 \mu \mathrm{g} / \mathrm{kg}[44,31,45,5]$. The DDX levels of the trial field ranged between $40-50 \mu \mathrm{g} / \mathrm{kg}$ which is even below the lower end of the published data. Furthermore, in comparison to surfactant studies published so far, the amounts of Tween applied to the soil was significantly lower (approx. $0.4 \%$ ) [41] and is an indirect effect resulting from drip-off from the sprayed plants.

Table 3. Bioaccumulation factor (BCF) of the analyzed Cucurbita pepo

\begin{tabular}{|l|l|l|l|}
\hline & Control area & Conventional area & Organic area \\
\hline DDX in soil $[\mu \mathrm{g} / \mathrm{kg}]$ dry weight & $42.6 \pm 1.9$ & $44.3 \pm 0.9$ & $44.9 \pm 3.3$ \\
\hline DDX in shoots $[\mu \mathrm{g} / \mathrm{kg}]$ dry weight & $429.5 \pm 67.3$ & $410.3 \pm 166.0$ & $704.5 \pm 234.5$ \\
\hline DDX in roots $[\mu \mathrm{g} / \mathrm{kg}]$ dry weight & $446.9 \pm 38.7$ & $502.1 \pm 30.9$ & $919.9 \pm 81.1$ \\
\hline DDX in pumpkin fruit $[\mu \mathrm{g} / \mathrm{kg}]$ dry weight & $26.3 \pm 15.0$ & $24.9 \pm 7.1$ & $63.4 \pm 20.9$ \\
\hline BCF shoots & 10.1 & 9.3 & 15.7 \\
\hline BCF root & 10.5 & 11.3 & 20.5 \\
\hline BCF fruit & 0.6 & 0.6 & 1.4 \\
\hline
\end{tabular}

${ }^{a}$ Data are given as mean values \pm standard deviation. BCF are based on mean values.

This is confirmed by Guo et al. [46], who concluded that Tween 80 could be suitable for remediation of DDT contaminated soil due to its stability against immediate degradation, but on the other hand due to a full biodegradability. Agnello et al. [23] and Mitton et al. [47] observed an increased degradability of lipophilic contaminants by microorganisms in the rhizosphere of alfalfa and willow plants after a soil treatment with Tween 80 in combination with citric acid, which could be interpreted as an effect of an increased mobility in the water phase.

Whitfield Aslund et al. [27] assumed that there is no direct correlation between the level of DDX in soil and the accumulated level of DDX in roots, but rather that the content of organic carbon in soil is a key driver. This is confirmed by Paul et al. [5], who demonstrated that the highest accumulation rates were observed on the soil with the lowest contamination levels, while there was no increase in the uptake from higher contaminated soil.

DDX and other lipophilic compounds are bound to soil organic matter, which can also be partially found in the water phase as dissolved organic carbon (DOC). It can be assumed that the boosting effect of particular surfactants on the mobility of DDX is the result of an increased release of DOC into the water. In particular, surfactants of the Tween class have a stronger water sorption tendency compared to other surfactants. Additionally, the higher accumulation in the organic section could be fostered by a partition-like interaction with the dissolved hydrophobic part of the surfactant and the dissolved humic materials [48-50].

Cucurbitacea have a high demand for water, therefore the cultivation area was irrigated. A study by Kelesy et al. [45] demonstrated a direct link between soil moisture and DDX accumulation. While this study also measured a dependence of the use of fertilizers, this cannot be of relevance here, as all of the sections were fertilized in comparable levels.

Guo et al. [46] evaluated the effect of the surfactant concentration of Tween 80 in hydroponic plant cultures on the resorption of PAHs and observed a direct correlation of the Tween level in solution and the BCF. The highest BCF values were monitored for ranges of approx. $6.6 \mathrm{mg} / \mathrm{L}$ surfactant in the water phase, which is comparable to the applied amounts in this study (approx. $11.3 \mathrm{mg} / \mathrm{L}$ ). This seems to be an optimal range, since significantly higher surfactant levels showed an inhibition of the uptake into the plants [51,52]. At this point, it has to be underlined that it is still not fully clear whether the mobilization effect is solely a result from the formulants Tween and vegetable oil or 
whether the active azadirachtin has an impact as well. Therefore, a potential influence of the actives on the mobilization of DDX with log Kow of $>6$ seems to be more likely for the less polar actives which was not observable. Furthermore, it is also still not clear which ratio of Tween, oil and water is the most efficient combination for mobilization. These open questions are subject to future research.

\section{CONCLUSION}

It has to be underlined that the effects observed in this study may pose a serious issue in regular agricultural use. Agronomists usually have a solid knowledge on the active compounds used in the formulations, but most commonly not on the formulation compounds. This is complicated by the fact that only substances with irritant or harmful properties are listed, while e.g. the toxicologically uncritical Tweens are commonly not named. As an effect, agronomists using such formulations on contaminated soils with high-accumulating crops may face an incalculable risk of boosting residual levels in their products by applying tested and approved agrochemicals.

For future evaluation and (re-)admission of agrochemicals, the impact of formulation adjuvants on the mobilization of incurred residues should move much more into the focus of systematic studies as before. It is more than likely that such effects will not be limited to DDX residues, but rather could be representative for other lipophilic contaminants.

Yet, this effect could also be considered as a potential chance: such Tween/oil treatments could be integrated into a regular crop protection regime using the respective agrochemical formulations. While a specific treatment with new surfactant/oil formulations, targeting to phytoremediation would most likely require additional regulatory efforts, the application of registered products such as the ones used in this study is already admitted.

For agronomists cultivating in areas with high DDX contaminations, this could be a sustainable approach to boost the efficacy of phytoremediation strategies without any additional treatments.

\section{ACKNOWLEDGEMENT}

The authors wish to thank the Konanz Stiftung Mannheim for their financial support.

\section{REFERENCES}

[1] Metcalf RL (1973) Century of DDT. J. Agric. Food Chem. 21 (4): 511-519.

[2] Isleyen M, Sevim P, White JC (2012) Accumulation of weathered p,p'-DDTs in grafted watermelon. J. Agric. Food Chem. 60 (4): 1113-1121.

[3] Tao S, Xu FL, Wang XJ, Liu WX, Gong ZM et al. (2005) Organochlorine Pesticides in Agricultural Soil and Vegetables from Tianjin, China. Environ. Sci. Technol. 39 (8): 2494-2499.

[4] White JC, Parrish ZD, Isleyen M, Gent MP, Iannucci-Berger W et al. (2005) Uptake of weathered p,p'DDE by plant species effective at accumulating soil elements. Microchemical Journal 81 (1): 148-155.

[5] Paul S, Rutter A, Zeeb BA (2015) Phytoextraction of DDT-Contaminated Soil at Point Pelee National Park, Leamington, ON, Using Cultivar Howden and Native Grass Species. J. Environ. Qual. 44 (4): 1201.

[6] Isleyen M, Sevim P, White JC (2012) Accumulation of weathered p, $\mathrm{p}^{\prime}$-DDTs in hybridized Cucurbita pepo cultivars. Environ. Toxico. Chem. 31 (8): 1699-1704.

[7] Geuß U., Hangen E., Schilling B., Spörlein P. Hintergrundwerte von anorganischen und organischen Schadstoffen in Böden Bayerns. Bayrisches Landesamt für Umwelt (LfU). 2011.

[8] Howard P. H., Meylan W. M. (1997) Handbook of Physical Properties of Organic Chemicals.

[9] Parfitt RL, Whitton JS, Susarla S (1995) Removal of DDT residues from soil by leaching with surfactants. Commun. Soil. Sci. Plan. 26 (13-14): 2231-2241.

[10] Yu Z, Yediler A, Yang M, Schulte-Hostede S (2012) Leaching behavior of enrofloxacin in three different soils and the influence of a surfactant on its mobility. J. Environ. Sci. 24 (3): 435-439.

[11] Mata-Sandoval JC, Karns J, Torrents A (2002) Influence of rhamnolipids and triton X-100 on the desorption of pesticides from soils. Environ. Sci. Technol. 36 (21): 4669-4675.

[12] Walters GW, Aitken MD (2001) Surfactant-enhanced solubilization and anaerobic biodegradation of 1,1,1-trichloro-2,2-bis(p-chlorophenyl)-ethane (DDT) in contaminated soil. Water Environ. Res. 73 (1): $15-23$.

[13] Karagunduz A, Gezer A, Karasuloglu G (2007) Surfactant enhanced electrokinetic remediation of DDT from soils. Sci. Total. Environ. 385 (1-3): 1-11. 
[14] Sánchez-Camazano M, Sánchez-Martín MJ, Delgado-Pascual R (2000) Adsorption and Mobility of Linuron in Soils As Influenced by Soil Properties, Organic Amendments, and Surfactants. J. Agric. Food Chem. 48 (7): 3018-3026.

[15] Asmus E, Popp C, Friedmann AA, Arand K, Riederer M (2016) Water Sorption Isotherms of Surfactants: A Tool To Evaluate Humectancy. J. Agric. Food Chem. 64 (26): 5310-5316.

[16] Mulligan C, Yong R, Gibbs B (2001) Surfactant-enhanced remediation of contaminated soil: a review. J. Geotech. Geoenviron. 60 (1-4): 371-380.

[17] Haigh SD (1996) A review of the interaction of surfactants with organic contaminants in soil. Sci. Total. Environ. 185 (1-3): 161-170.

[18] Volkering F, Breure A, Rulkens W (1997) Microbiological aspects of surfactant use for biological soil remediation. Biodegradation 8 (6): 401-417.

[19] Wang X, Chen J, Lv C (2015) Evaluation of foam surfactant for foam-flushing technique in remediation of DDT-contaminated soil using data envelopment analysis method. Environ. Sci. Pollut. Res. 22 (4): 2994 3003.

[20] Yu Z, Yediler A, Yang M, Schulte-Hostede S (2012) Leaching behavior of enrofloxacin in three different soils and the influence of a surfactant on its mobility. J. Environ. Sci. 24 (3): 435-439.

[21] Alden A, Jun N, Damian S, Aitken MD, Adrion AC et al. (2016) Screening Nonionic Surfactants for Enhanced Biodegradation of Polycyclic Aromatic Hydrocarbons Remaining in Soil After Conventional Biological Treatment. Environ. Sci. Technol. 50 (7): 3838-3845.

[22] Zhang A, Chen Z, Ahrens L, Liu W, Li Y-F (2012) Concentrations of DDTs and Enantiomeric Fractions of Chiral DDTs in Agricultural Soils from Zhejiang Province, China, and Correlations with Total Organic Carbon and pH. J. Agric. Food Chem. 60 (34): 8294-8301.

[23] Agnello AC, Huguenot D, van Hullebusch ED, Esposito G (2015) Phytotoxicity of citric acid and Tween(R) 80 for potential use as soil amendments in enhanced phytoremediation. Int. J. Phytoremediation 17 (7): 669-677.

[24] Zhu Z-q, Yang X-e, Wang K, Huang H-g, Zhang X et al. (2012) Bioremediation of Cd-DDT cocontaminated soil using the Cd-hyperaccumulator Sedum alfredii and DDT-degrading microbes. J. Hazard. Mater. 235-236: 144-151.

[25] Passatore L, Rossetti S, Juwarkar AA, Massacci A (2014) Phytoremediation and bioremediation of polychlorinated biphenyls (PCBs): State of knowledge and research perspectives. J. Hazard. Mater. 278: 189-202.

[26] Sun Y, Zhou Q, Xu Y, Wang L, Liang X (2011) Phytoremediation for co-contaminated soils of benzoapyrene $(\mathrm{BaP})$ and heavy metals using ornamental plant Tagetes patula. J. Hazard. Mater. 186 (2-3): 2075-2082.

[27] Whitfield Åslund ML, Lunney AI, Rutter A, Zeeb BA (2010) Effects of amendments on the uptake and distribution of DDT in Cucurbita pepo ssp pepo plants. Environ. Pollut. 158 (2): 508-513.

[28] Mattina, Isleyen M, Eitzer BD, Iannucci-Berger W, White JC (2006) Uptake by Cucurbitaceae of SoilBorne Contaminants Depends upon Plant Genotype and Pollutant Properties. Environ. Sci. Technol. 40 (6): 1814-1821.

[29] Huelster A, Mueller JF, Marschner H (1994) Soil-Plant Transfer of Polychlorinated Dibenzo-p-dioxins and Dibenzofurans to Vegetables of the Cucumber Family (Cucurbitaceae). Environ. Sci. Technol. 28 (6): 1110-1115.

[30] Ye Q, Puri RK, Kapila S, Yanders AF (1992) Studies on the transport and transformation of PCBs in plants. Chemosphere 25 (7): 1475-1479.

[31] Lunney AI, Zeeb BA, Reimer KJ (2004) Uptake of Weathered DDT in Vascular Plants: Potential for Phytoremediation. Environ. Sci. Technol. 38 (22): 6147-6154.

[32] Lunney AI, Rutter A, Zeeb BA (2010) Effect of organic matter additions on uptake of weathered DDT by Cucurbita pepo ssp. pepo cv. Howden. Int. J. Phytoremediation 12 (4): 404-417.

[33] La Torre-Roche R de, Hawthorne J, Deng Y, Xing B, Cai W et al. (2012) Fullerene-enhanced accumulation of p,p'-DDE in agricultural crop species. Environ. Sci. Technol. 46 (17): 9315-9323.

[34] Whitfield Åslund ML, Zeeb BA, Rutter A, Reimer KJ (2007) In situ phytoextraction of polychlorinated biphenyl - (PCB)contaminated soil. Sci. Total. Environ. 374 (1): 1-12.

[35] Wang X, White JC, Gent MPN, Iannucci-Berger W, Eitzer BD et al. (2004) Phytoextraction of Weathered p,p'-DDE by Zucchini (Cucurbita pepo) and Cucumber (Cucumis sativus) Under Different Cultivation Conditions. International Journal of Phytoremediation 6 (4): 363-385. 
[36] White JC, Parrish ZD, Gent MPN, Iannucci-Berger W, Eitzer BD et al. (2006) Soil amendments, plant age, and intercropping impact p,p'-DDE bioavailability to Cucurbita pepo. J. Environ. Qual. 35 (4): 992-1000.

[37] White JC (2001) Plant-facilitated mobilization and translocation of weathered 2,2-bis(p-chlorophenyl)-1,1dichloroethylene (p,p'-DDE) from an agricultural soil. Environ. Toxico. Chem. 20 (9): 2047-2052.

[38] White JC, Mattina MI, Lee WY, Eitzer BD, Iannucci-Berger W (2003) Role of organic acids in enhancing the desorption and uptake of weathered p,p'-DDE by Cucurbita pepo. Environmental pollution (Barking, Essex : 1987) 124 (1): 71-80.

[39] Suzuki M, Aizawa N, Okano G, Takahashi T (1977) Translocation of polychlorobiphenyls in soil into plants: A study by a method of culture of soybean sprouts. Arch. Environ. Contam. Toxicol. 5 (1): $343-$ 352.

[40] Wu N, Zhang S, Huang H, Shan X, Christie P et al. (2008) DDT uptake by arbuscular mycorrhizal alfalfa and depletion in soil as influenced by soil application of a non-ionic surfactant. Environ. Pollut. 151 (3): $569-575$.

[41] Neitsch J, Schwack W, Weller P (2016) How Do Modern Pesticide Treatments Influence the Mobility of Old Incurred DDT Contaminations in Agricultural Soils. J. Agric. Food Chem.

[42] (1993) VO (EWG) 315/93 Verordung zur Festlegung von gemeinschaftlichen Verfahren zur Kontrolle von Kontaminanten in Lebensmitteln.

[43] SANCO/12571/2013 (2013) Guidance Document on Analytical Quality Control and Validation Procedures for Pesticide Residues Analysis in Food and Feed. European Commission Health \& Consumer Protection Directorate.

[44] White JC (2002) Differential bioavailability of field-weathered p,p'-DDE to plants of the Cucurbita and Cucumis genera. Chemosphere 49 (2): 143-152.

[45] Kelsey JW, Colino A, Koberle M, White JC (2006) Growth conditions impact 2,2-bis(p-chlorophenyl)1,1-dichloroethylene (p,p'-DDE) accumulation by Cucurbita pepo. Int. J. Phytoremediation 8 (3): $261-271$.

[46] Guo P, Chen W, Li Y, Chen T, Li L et al. (2014) Selection of surfactant in remediation of DDTcontaminated soil by comparison of surfactant effectiveness. Environ. Sci. Pollut. Res. Int. 21 (2): 13701379.

[47] Mitton FM, Gonzalez M, Pena A, Miglioranza KSB (2012) Effects of amendments on soil availability and phytoremediation potential of aged p,p'-DDT, p,p'-DDE and p,p'-DDD residues by willow plants (Salix sp.). J. Hazard. Mater. 203-204: 62-68.

[48] Kile DE, Chiou CT (1989) Water solubility enhancements of DDT and trichlorobenzene by some surfactants below and above the critical micelle concentration. Environ. Sci. Technol. 23 (7): 832-838.

[49] Chiou CT, Malcolm RL, Brinton TI, Kile DE (1986) Water solubility enhancement of some organic pollutants and pesticides by dissolved humic and fulvic acids. Environ. Sci. Technol. 20 (5): 502-508.

[50] Chiou CT, Kile DE, Brinton TI, Malcolm RL, Leenheer JA et al. (1987) A comparison of water solubility enhancements of organic solutes by aquatic humic materials and commercial humic acids. Environ. Sci. Technol. 21 (12): 1231-1234.

[51] Gao Y, Shen Q, Ling W, Ren L (2008) Uptake of polycyclic aromatic hydrocarbons by Trifolium pretense L. from water in the presence of a nonionic surfactant. Chemosphere 72 (4): 636-643.

[52] White JC, Peters R, Kelsey JW (2007) Surfactants differentially impact p,p'-DDE accumulation by plant and earthworm species. Environ. Sci. Technol. 41 (8): 2922-2929.

Citation: Julia Neitsch, Wolfgang Schwack, Philipp Weller, "Modern Agrochemicals Influence Bioaccumulation of Incurred DDT Soil Residues in Pumpkins - Residue Risk or a Chance for Phytoremediation?" International Journal of Research in Environmental Science, vol. 4, no. 3, p. 13-23, 2018. http://dx.doi.org/ 10.20431/2454-9444.0403002

Copyright: (C) 2018 Authors. This is an open-access article distributed under the terms of the Creative Commons Attribution License, which permits unrestricted use, distribution, and reproduction in any medium, provided the original author and source are credited. 